\title{
Building Energy Efficiency Design for Waiting Halls of Railway Stations in the Hot- summer and Cold-winter Region
}

\author{
Yang XiuE \\ ${ }^{I}$ School of Civil Engineering, Tangshan College, Hebei, China
}

Received 6 January 2017; Accepted 12 March 2017

\begin{abstract}
Waiting halls of railway stations are typically structured as large-spaced buildings and consume a large amount of energy This study aimed to explore the effect of the law of thermal properties of waiting hall enveloped in railway stations on building energy consumption and to disclose the energy-saving potential of waiting hall of railway stations. A waiting hall model based on the waiting hall of the Chengdu Railway Station was established using the Quick Energy Simulation Tool (eQUEST). Numerical simulation on energy consumption of waiting hall was conducted by changing the performance parameters of building envelope and area ratio of skylight and sun-shading mode. The influences of thermal properties of building envelope on energy consumption were discussed. Results demonstrate that, when the waiting hall of the railway station applies a glass curtain wall as the envelope, the coated insulting glasses used contribute to the low building energy consumption with an energy saving rate of 5.3\%. With the increase in area ratio of skylight, building energy consumption decreases first and then increases. The rate reaches the valley at $20 \%$ area ratio of skylight. Sunshading measures on the glass curtain wall and skylight, especially external sun-shading measure, can significantly reduce building energy consumption. The findings provide theoretical basis for building energy efficiency design for the waiting halls of railway stations in regions with hot summer and cold winter, and have important theoretical significance and engineering application value in promoting building energy efficiency design in the said regions.
\end{abstract}

Keywords: railway station, building envelope, energy-saving design

\section{Introduction}

Several railway stations have been constructed since the rapid development of high-speed railways in China [1]. A high, large, and transparent building design for the waiting halls of railway stations is proposed to provide passengers with safe, convenient, and comfortable environment [2]. Under such design philosophy, large-area glass curtain wall and skylight are highly utilized as the building envelope of waiting halls of railway stations. The design brings a new challenge to building energy consumption of waiting hall of railway stations. The thermophysical and optical properties of glass present different effects on the thermal environment and energy consumption of building structures. On the one hand, building energy consumption caused by glass structures in winter with large difference between indoor and outdoor temperatures is mainly manifested as energy consumption of heat transfer by temperature difference. The heat transfer coefficient is the main index that is used in measuring the energy-saving performance of glass. Under air conditioning conditions in summer, building energy consumption from glass structures is manifested as solar radiation energy consumption. The sun-shading coefficient is the main index that is used to measure the heat-insulating property of glass. On the other hand, the visible light transmittance of glass is an important parameter in

*E-mail address: wuhaidongxiaozi@126.com

ISSN: 1791-2377 @ 2017 Eastern Macedonia and Thrace Institute of Technology. All rights reserved. measuring lighting performance. The structure influences lighting energy consumption directly. Visible light transmittance is negatively correlated with energy consumption of the lighting system. The heat transfer coefficient, shading coefficient, and visible light transmittance of glass are closely related to one another. High heat transfer coefficient leads to high shading coefficient and high visible light transmittance. Analyzing the building energy consumption of waiting hall of railway station during the early stage of architectural design by use of simulation software is important to the building energy efficiency design of the said structure. The effects of the thermal and optical properties of the building envelope on building energy consumption should be discussed, and the optimal envelope combination should be determined.

\section{State of the art}

The design of envelope components (roof, wall, thermal insulation materials, door and window, and sun-shading facilities) affects building energy consumption [3]. For example, heat consumption of envelope accounts for over one-third of heat consumption for heating [4]. Improving the thermal properties of the building envelope can reduce outdoor heat transfer to indoor space in summer and decrease indoor heat loss in winter. As a result, the thermal environment of building improves and the cold and heat consumptions decrease. 
Under continuous energy consumption pattern, exterior wall/external insulation can save energy for heating and cooling of buildings. Kossecka et al. [5] analyzed the cooling and heating loads of single-story residential architectures in six climatic regions in America under the continuous energy consumption pattern by use of the DOE-2 software. They found that exterior wall/external insulation can decrease cooling and heating loads in buildings. Under intermittent energy consumption pattern, exterior wall/external insulation can decrease heating load of buildings but may not reduce cooling load. Tummu et al. [6, 7] in Thailand and Ihara et al. [8] in Japan discovered that, under intermittent energy consumption pattern, exterior wall/external insulation of buildings shows an "anti-energy saving" effect. Energy-saving efficiency of insulation measures is related to local climatic conditions. Pan et al. [9] studied the exterior wall/external insulation in Beijing, Shanghai, and Guangzhou. They found that the best exterior wall/external insulation is achieved in Beijing, a case in which heating load plays a major role. The critical thickness of exterior wall/external insulation in Shanghai is $26 \mathrm{~mm}$, and exterior wall/external insulation shows an obvious "antienergy saving" effect in Guangzhou. Ruan Fang et al. [10] established a two-dimensional household heat transfer model and then dynamically analyzed the energy-saving effect after internal and external insulation of residential building walls. They found that the exterior wall/external insulation hinders heat dissipation of walls to the outside environment and shows an "anti-energy saving" effect during cooling in summer night. The internal insulation technique can reduce the cooling load of air conditioners.

Improving the thermal properties of external window can reduce energy consumption for air-conditioning and illumination of buildings significantly. Chu Hongliang et al. [11] analyzed the energy-saving effect of coated insulating glass. They reported that using coated insulating glass on external windows in regions with hot summer and cold winter can reduce air-conditioning energy consumption of buildings effectively. C. K. Cheung et al. [12] simulated the peak cooling load and total cooling capacity of a high-rise apartment with the TRNSYS software and discussed the effects of glass types, window size, and sun-shading measures on cooling demands and peak cooling load. Athanassios [13] determined the functional relationship between energy consumption for air-conditioning and illumination in outer region of public buildings, as well as window/wall ratio and sun-shading characteristic parameters. They found that using combined mobile controllable sunshading system and light control system can reduce the annual average energy consumption of buildings. Wang Peihao et al. [14] simulated the energy consumption of existing buildings in Xi'an by use of the Quick Energy Simulation Tool (eQUEST) software. They concluded that using double-layer insulating glass as the external window can save energy by up to $10 \%$. Ma Xiaowen et al. [15] compared the measured lighting coefficient and electricity consumption, and they concluded that using combined blind shading and low-E insulating glass windows to northwest buildings can reduce air-conditioning energy consumption effectively.

Obviously, most studies on building energy efficiency design mainly concentrates on insulation and external window of building envelope and few studies discuss the energy efficiency design of buildings with glass curtain wall and large-area skylight. The present study aimed to explore the energy-saving potentials of waiting hall of railway stations using the building model of the waiting hall of the Chengdu Railway Station. Then, the influences of the thermal and optical properties of building envelope on building energy consumption were analyzed with the eQUEST software.

The rest of the study is organized as follows. Section 3 establishes the waiting hall model of the Chengdu Railway Station. Section 4 discusses the simulation results and the effects of the thermal properties of exterior wall, area ratio of skylight, and sun-shading mode on the energy consumption of waiting hall of railway stations. Section 5 elaborates the conclusions of the study.

\section{Methodology}

This study simulated a building model with climatic characteristics, building structure, and service conditions. Next, the energy consumption of the building model was analyzed with the eQUEST software.

\subsection{Mathematical model}

The eQUEST software was developed by the United States Department of Energy based on DOE-2. Energy consumption is calculated by the running schedule and power of internal energy consumption module. The calculation formula is

$W=n w$

where,

$W$ is the total electricity consumption (W),

$n$ is the run time (s), and $w$ is the equipment power (W).

The run time and run power of equipment in the waiting hall of railway stations were fixed and could therefore be directly calculated using the abovementioned formula. The run time and run power of the illumination system were controlled by indoor illuminance, which is related to local meteorological parameters, transmittance of building envelope, and illuminating system. In establishing the building model, the simulation software determined the run time and run power of the illumination system automatically by inputting the said boundary conditions. The results could be calculated from Formula (1). On the basis of the necessary cooling and heating loads of buildings, the energy consumption module of air-conditioning system was determined with additional consideration of the fresh air load, run time of equipment, control strategy of airconditioning system, and natural changes of indoor state. eQUEST calculated the cooling load of building envelope by the reaction coefficient method. Considering the heat storage capacity of building envelope, heat conversion into cooling load was accompanied with attenuation and delay. The calculation equation is

$$
Q=\sum_{j=0}^{\infty} Y(j)\left(t_{z}(n-j)-\sum_{j=0}^{\infty} Z(j)\left(t_{r}(n-j)\right.\right.
$$

where $Y(j)$ is the heat transfer reaction coefficient of the building envelope, $Z(j)$ is the endothermic reaction coefficient of the building envelope, $t_{z}(n-j)$ is the outdoor comprehensive temperature $\left({ }^{\circ} \mathrm{C}\right)$ at $n-j$, and $t_{r}(n-j)$ is the indoor temperature $\left({ }^{\circ} \mathrm{C}\right)$ at $n-j$. 
When the indoor temperature is constant, the formula can be simplified as

$Q=\sum_{j=0}^{\infty} Y(j)\left(t_{z}(n-j)-k t_{r}\right.$

where $k$ is the heat transfer coefficient of building envelope $\left(W / m^{2} \cdot K\right)$.

The calculation formula of indoor temperature is

$$
\begin{aligned}
& \frac{\partial t(x, \tau)}{\partial t}=\alpha \frac{\partial t^{2}(x, \tau)}{\partial t^{2}} \\
& q(x, \tau)=-\lambda \frac{\partial t(x, \tau)}{\partial x}
\end{aligned}
$$

where $\alpha$ is the thermal diffusivity of wall materials ( $\left.m^{2} / h\right), \lambda$ is the thermal conductivity of materials $\left(W / m^{2} \cdot K\right)$, and $q$ is the capacity of heat transmission of wall body $\left(W / m^{2}\right)$.

\subsection{Building model}

\subsubsection{Building model}

The Chengdu East Railway Station comprises one ground floor and two aboveground floors and is shown in Fig. 1. The underground floor is the exit, the first floor is the platform, and the second floor is the waiting hall. The established building model is based on the waiting hall of the Chengdu East Railway Station (Figs. 2 and 3). This waiting hall is $280 \mathrm{~m}$ long and $145 \mathrm{~m}$ wide with an area of approximately $40,600 \mathrm{~m} 2$. The architectural plane is shown in Fig. 4. In accordance with the characteristics and development trend of modern buildings, a glass curtain wall was used as the waiting hall envelope. Moreover, the skylight area of the waiting hall was designed at $30 \%$ to increase natural lighting. The architectural plan of the waiting hall of the Chengdu East Railway Station was input into eQUEST, and the building model of the waiting hall was constructed by changing the scale height and area ratio of the skylight (Fig. 5).

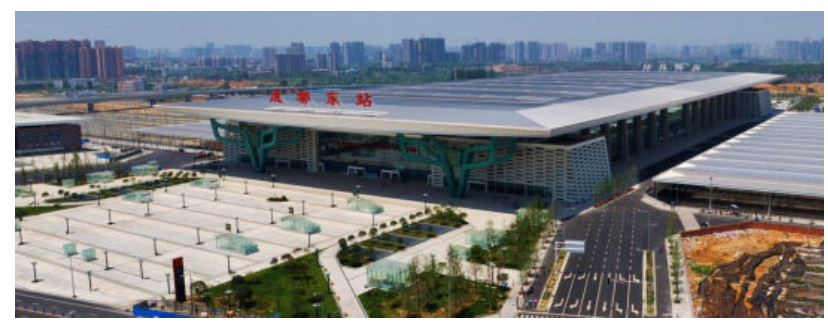

Fig. 1. Appearance of the Chengdu East Railway Station

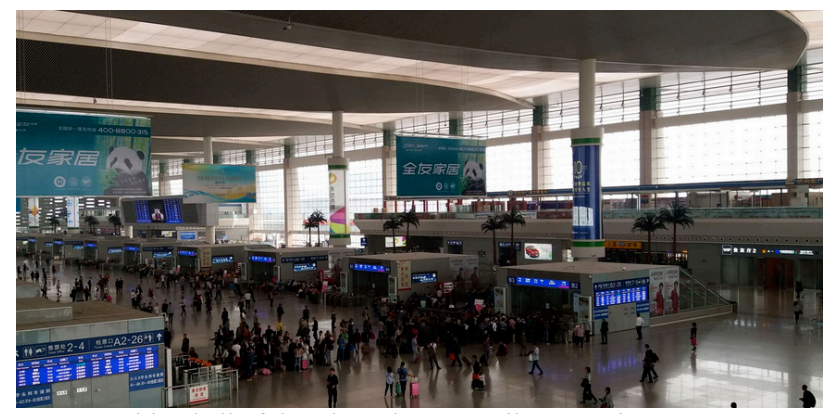

Fig. 2. Waiting hall of the Chengdu East Railway Station

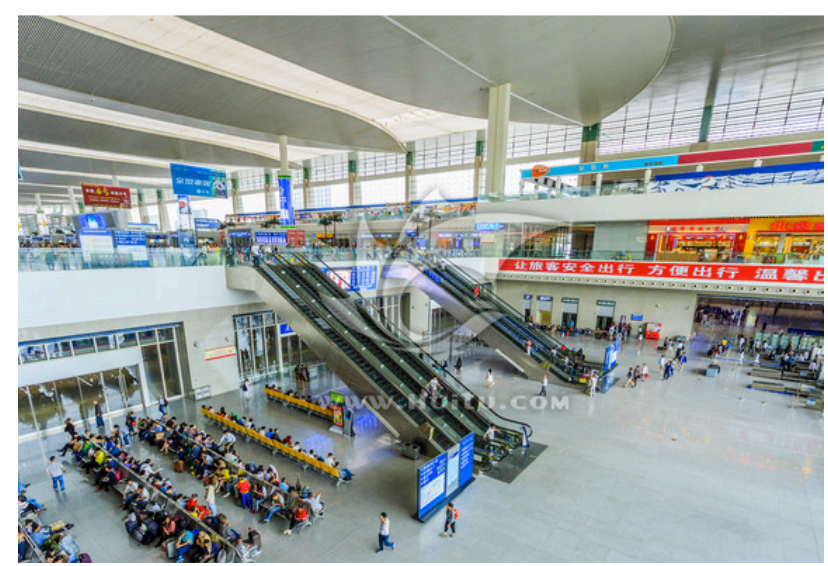

Fig. 3. Waiting hall of the Chengdu East Railway Station

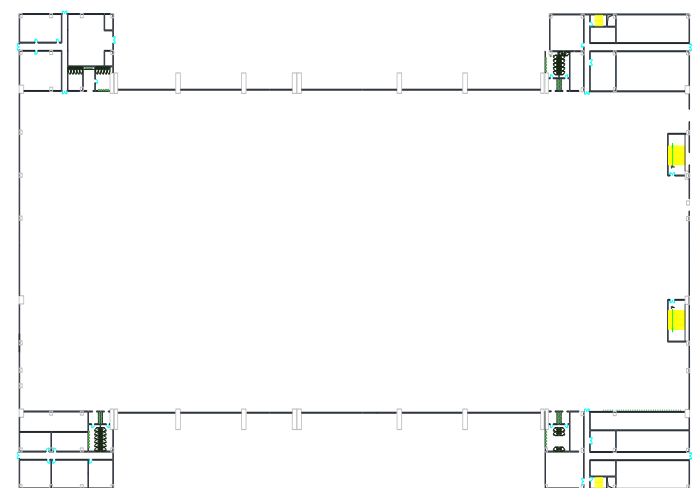

Fig. 4. Architectural plan of the waiting hall of the Chengdu East Railway Station

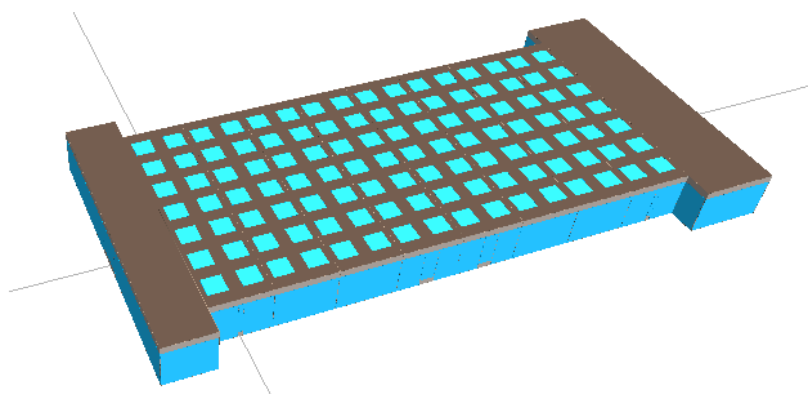

Fig. 5. Building model of the waiting hall of the Chengdu East Railway Station

\subsubsection{Parameter setting}

In simulating the energy consumption of the building model, the main factors that influenced building energy consumption were envelope parameters, local meteorological parameters, indoor design parameters, type of air-conditioning system, and ventilation setting. Therefore, after the building model was established, inputting the said parameters accurately was utmost important to simulate the building energy consumption in the waiting hall of the railway station.

\section{(1) Envelope parameters}

The envelope materials and heat transfer coefficients of the waiting hall of the Chengdu East Railway Station are listed in Table 1. Considering the lack of some envelope components in the simulation software, corresponding parameters should be changed close to real situations. 
(2) Meteorological parameters

The Chengdu East Railway Station is located in Chenghua District, Chengdu City. The meteorological data of the typical meteorological year in Chengdu City were collected (Fig. 6) for the study. July is the hottest month and January is the coldest month in the year in the said region. The daily highest temperature is $34.8{ }^{\circ} \mathrm{C}$ and the daily lowest temperature is $-0.9{ }^{\circ} \mathrm{C}$.

\section{(3) Indoor design parameters}

The indoor design parameters in accordance with the Code for Railway Station Architectural Design are listed in Table 2 .

Table 1. Envelope materials and total heat transfer coefficients

\begin{tabular}{|c|c|c|}
\hline Envelope & Materials (from inside to outside) & $\begin{array}{l}\text { Total heat transfer } \\
\text { coefficient }\end{array}$ \\
\hline Roof & Color plate mineral wool sandwich panel $50 \mathrm{~mm}$ (Solar radiation absorbance $=0.6$ ) & 0.75 \\
\hline Outer wall & $\begin{array}{l}\text { Glass curtain wall (sun-shading coefficient }=0.83 \text {; solar heat gain coefficient }=0.722 ; \text { solar } \\
\text { transmittance }=0.63 \text { ) }\end{array}$ & 3.10 \\
\hline House board & $300 \mathrm{~mm}$ reinforced concrete & 0.8 \\
\hline $\begin{array}{l}\text { External } \\
\text { windows }\end{array}$ & Window $/$ wall ratio $=30 \%$; glass type is consistent with the curtain wall & 3.10 \\
\hline Outer door & Glass (same with glass curtain wall) & 3.10 \\
\hline Skylight & Area ratio of skylight is $30 \%$, and the glass type is consistent with the glass curtain wall. & 3.10 \\
\hline
\end{tabular}

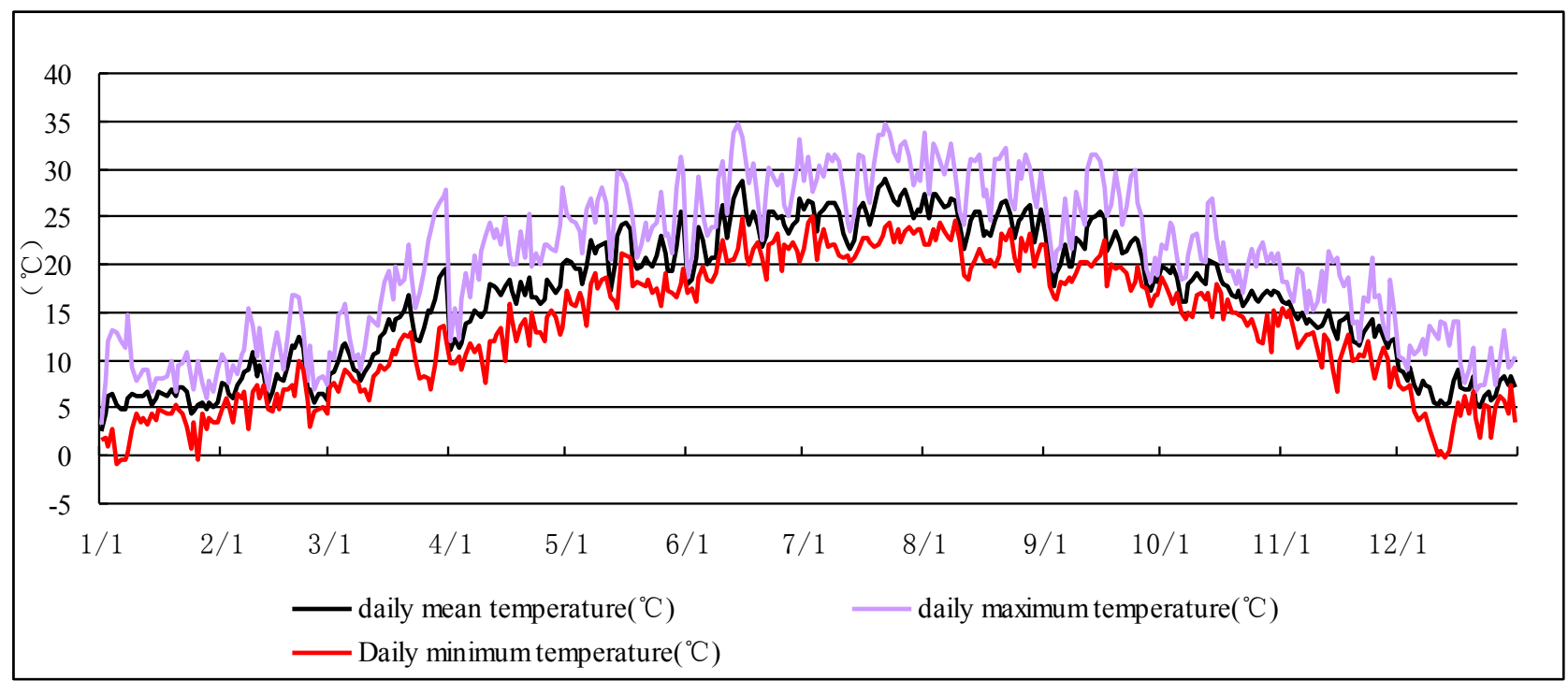

Fig. 6. Statistics on annual dry-bulb temperature in Chengdu

Table 2. Indoor design parameters

\begin{tabular}{c|c|c|c|c|c|c} 
& \multicolumn{2}{|c|}{$\begin{array}{c}\text { Temperature } /{ }^{\circ} \mathbf{C} \\
\text { Summer }\end{array}$} & \multicolumn{2}{c|}{$\begin{array}{c}\text { Relative humidity } / \% \\
\text { Wumter }\end{array}$} & $\begin{array}{c}\text { Personnel density } \\
\left.\text { (person }(\mathbf{s}) / \mathrm{m}^{2}\right)\end{array}$ & $\begin{array}{c}\text { Fresh air volume } \\
\left(\mathrm{m}^{3} / \mathrm{h} \cdot \text { person }\right)\end{array}$ \\
\hline Waiting hall & 26 & 18 & 55 & -- & 0.91 & 10 \\
\hline
\end{tabular}

Table 3. Indoor design parameters

\begin{tabular}{c|c|c|c}
\hline Time & Thermal perturbation coefficient & Time & Thermal perturbation coefficient \\
\hline $0: 00$ & 0.02 & $12: 00$ & 0.4 \\
$1: 00$ & 0.02 & $13: 00$ & 0.4 \\
$2: 00$ & 0.02 & $14: 00$ & 0.643 \\
$3: 00$ & 0.02 & $15: 00$ & 0.7875 \\
$4: 00$ & 0.02 & $16: 00$ & 0.5635 \\
$5: 00$ & 0.0375 & $17: 00$ & 0.7875 \\
$6: 00$ & 0.15 & $18: 00$ & 0.643 \\
$7: 00$ & 0.4 & $19: 00$ & 0.7875 \\
$8: 00$ & 0.4 & $20: 00$ & 1.0000 \\
$9: 00$ & 0.4 & $21: 00$ & 0.5635 \\
$10: 00$ & 0.225 & $22: 00$ & 0.1125 \\
$11: 00$ & 0.1125 & $23: 00$ & \\
\hline
\end{tabular}

(5) Settings of illumination system 
The illumination power in the waiting hall was designed to be $20 \mathrm{w} / \mathrm{m}^{2}$ and the building illuminance was $450 \mathrm{~lx}$. Illumination was controlled by $10 \%$ minimum continuous light tuning. The illumination sensor was installed at 50\% depth of the waiting hall and $0.76 \mathrm{~m}$ below the ceiling. The indoor illuminance was controlled to be 20 and the maximum glare was 20 .

(6) Equipment setting

The thermal perturbation of equipment was set to 3 $\mathrm{W} / \mathrm{m} 2$.

(7) Air conditioning system and ventilation setting

The air conditioning system applied an all-air system, and the cold and heat sources used the ground source heat pump. The air conditioning system was turned on during the air-conditioning and heating period. The permeation ventilation times were set to $0.5 / \mathrm{h}$.

\section{Results and discussion}

\subsection{Analysis of simulation results on building energy consumption}

Parameters were set on the basis of the building model of the waiting hall in Section 3.2. The simulation calculation was performed in accordance with the building design mode. According to simulation results, the total building energy consumption of the waiting hall of the Chengdu East Railway Station is $8,419,794 \mathrm{KWh}$. The energy consumption of the air-conditioning system is 5,462,759 KWh (64.9\%), the energy consumption of the illumination system is
$2,581,000 \mathrm{KWh}(30.6 \%)$, and the energy consumption of others accounts for $4.5 \%$. This result indicates that airconditioning and illumination systems are significant users of building energies and have large potential in energy saving.

One important index that influences the energy consumption of air-conditioning system is the annual accumulative cooling and heating loads of buildings. Building cooling and heating loads are mainly related to two factors: the internal disturbance by persons and equipment in the rooms of the building, and the thermal properties of building envelope. The internal disturbance by persons and equipment in the main functional rooms is relatively determined and cannot be optimized by building design. As a result, optimized design of the building envelope is an effective means to reduce building energy consumption.

\subsection{Optimization design}

\subsubsection{Optimization design of outer walls}

The external walls of the building model applied the glass curtain wall. These walls are beautifully structured, of good natural lighting, and consume low energy for illumination. Nevertheless, good natural lighting can cause solar heat gain and increase the air-conditioning loads. Improper design can result in unnecessary energy waste. The optimization design of glass curtain wall changes the parameters of glass curtain wall in the building model in simulating the building energy consumption of the waiting hall of railway stations. The specific parameters of glass curtain wall are listed in Table 4.

Table 4. Glass parameter

\begin{tabular}{c|c|c|c}
\hline Glass types & $\begin{array}{c}\text { Heat transfer coefficient } \\
\left(\mathrm{W} / \mathrm{m}^{2} \cdot \mathrm{K}\right)\end{array}$ & Shading coefficient & Visible light transmission \\
\hline Insulating glass & 3.1 & 0.83 & 0.63 \\
Transparent glass & 6.2 & 0.95 & 0.88 \\
Low-radiation glass & 1.8 & 0.69 & 0.77 \\
Coated insulating glass & 2.5 & 0.45 & 0.44 \\
Heat-reflecting glass & 2.95 & 0.27 & 0.18 \\
\hline
\end{tabular}

The simulation results in Fig. 7 show that the building energy consumptions of the waiting hall using heatreflecting glass, coated insulating glass, and low-radiation glass as the glass curtain wall are lower than that of the original building. This condition is mainly due to that solar radiation heat gain accounts for a large proportion in the heat gain of building envelope in summer. Consequently, the sunshading coefficient of curtain wall becomes the most important influencing factor of the total building energy

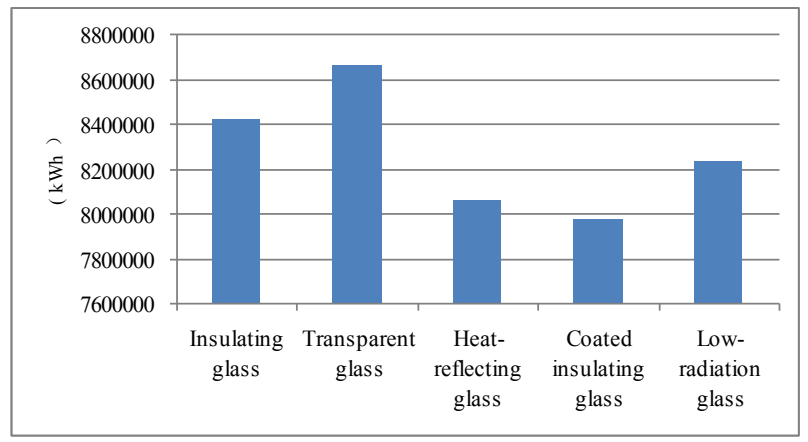

Fig. 7. Annual building energy consumption consumption, while the heat transfer coefficient becomes the secondary important factor (Fig. 8). The opposite effect is observed in winter (Fig. 9). In regions with hot summer and cold winter during which the cooling loads play the major role, the energy consumption by air-conditioning system in summer is the most important influencing factor of the total building energy consumption.

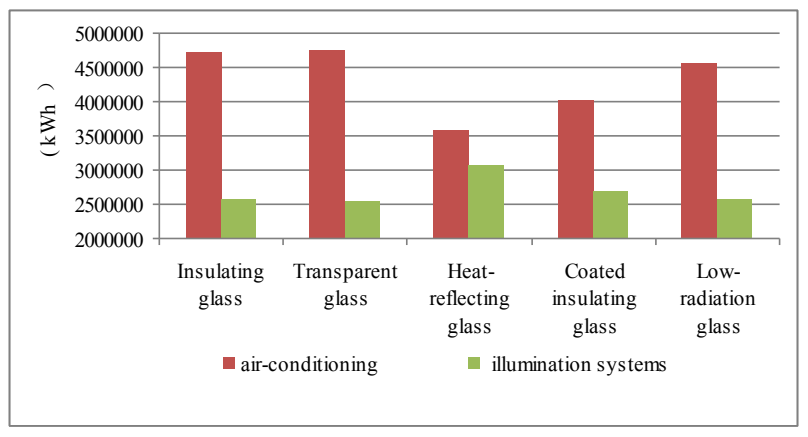

Fig.8. Energy consumption of air-conditioning and illumination systems in summer 


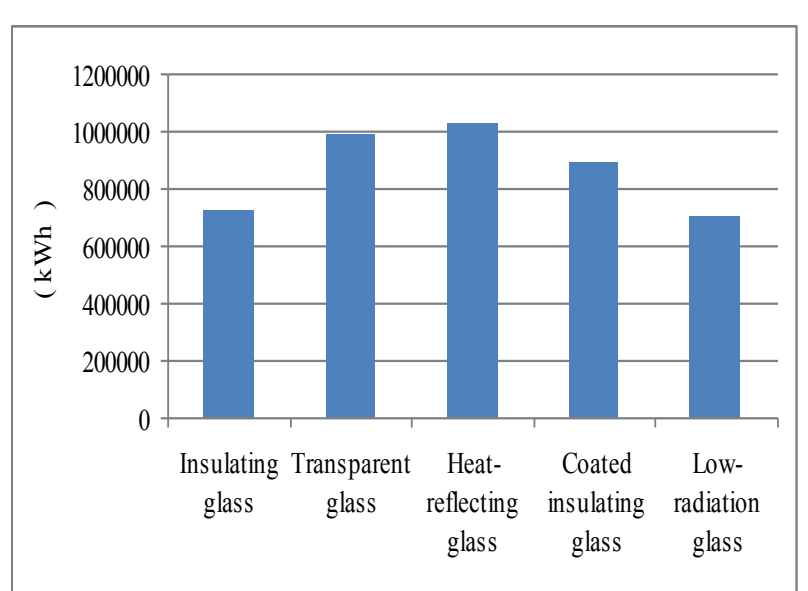

Fig. 9. Energy consumption of air-conditioning system in winter

Heat-reflecting glass hinders the transmittance of solar infrared thermal radiation waveband and projection of visible lights. Thus, the visible light transmittance of heatreflecting glass is only 0.18 , thereby resulting in high energy consumption for illumination. Although the coated insulating double-silver glass has poor sun-shading performance, the structure mainly hinders the transmittance of infrared thermal radiation waveband in solar radiation and allows the transmittance of visible lights. The visible light transmittance reaches 0.44 , thereby resulting in low energy consumption for illumination (Fig. 8). Obviously, the coated insulating double-silver glass can meet the natural lighting requirements of the waiting hall of railway stations. Therefore, the highest building energy efficiency is achieved when using coated insulating glass as the curtain wall. Compared with the reference building, the energy consumption is decreased by $442,475 \mathrm{kWh}$ with an energysaving rate of $5.3 \%$.

\subsubsection{Optimization design of skylight}

Skylight is an important source of natural illumination in the waiting halls of railway stations. The structure is characterized by a large area, good natural illumination, and low energy consumption. Meanwhile, energy consumption of air-conditioning system increases with the increase in solar radiation heat gain. Therefore, appropriate skylight design plays an important role in reducing building energy consumption. The optimized design of the skylight in this part mainly focused on simulating the energy consumption of waiting hall with different area ratios of skylight $(35 \%$, $25 \%, 20 \%, 15 \%, 10 \%$, and $5 \%$ ). Through simulation, the influences of area ratio of skylight on building energy consumptions were analyzed and the area ratio for the highest energy-saving efficiency was identified. The skylight glass used coated insulating glasses.

The simulation results in Fig. 10 show that the energy consumption of building illumination system decreases gradually with the increase in area ratio of skylight. However, the energy consumption of air-conditioning system increases gradually in summer while shows an inverted V-shaped variation law in winter. The annual energy consumption presents a $\mathrm{V}$-shaped variation law. The lowest annual building energy consumption (7,744,862 kWh) is achieved when the area ratio of skylight is $20 \%$ with an energy-saving rate of $8 \%$.

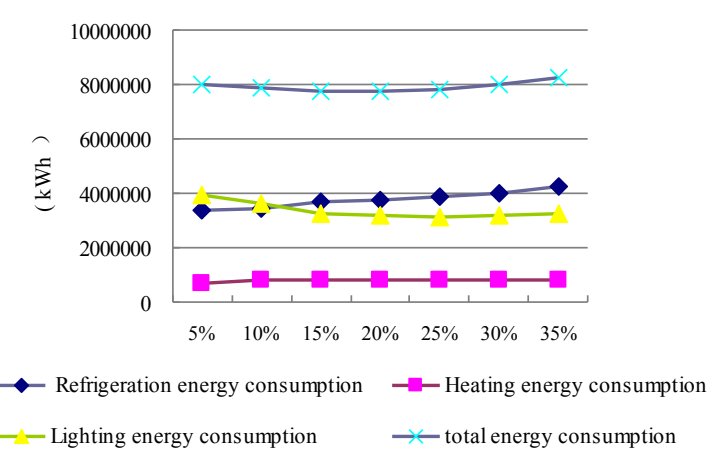

Fig. 10. Effects of area ratio of skylight on building energy consumption

\subsubsection{Effects of sun-shading of skylight on building energy consumption}

Solar radiation significantly influences heating and airconditioning loads. On building windows and walls in regions with hot summer and cold winter, solar radiation should be reduced in summer as much as possible to decrease the energy consumption of air-conditioning system. On the contrary, solar radiation should be increased in winter as much as possible to reduce the energy consumption of heating system. Therefore, a reasonable sunshading design is important in energy-saving performance. Sun-shading modes can be divided into three types, namely, afforestation, architectural, and special. Among them, special sun-shading includes external, blind internal, internal with coating film, and external with coating film, among others. In this section, the influences of glass curtain wall and sun-shading mode of skylight on the building energy consumption of waiting hall are discussed. External sunshading with coating film and internal sun-shading with coating film were used in the simulation. ETFE film was used as the coating film in internal and external sun-shading modes (sun-shading coefficient is 0.5 ).

The simulation results in Fig. 11 show that the total building energy consumption decreases significantly after applying sun-shading measures on the glass curtain walls and external windows of waiting hall. The reason is that the decrease in solar radiation heat gain in the waiting hall increases the energy consumption of air-conditioning system in winter whereas decreases that in summer. However, the energy consumption of illumination system increases to some extent. Building energy consumption decreases dramatically (approximately 12\%) after external sun-shading measures are used on the glass curtain wall and outer windows. Thus, using external sun-shading measure is recommended.

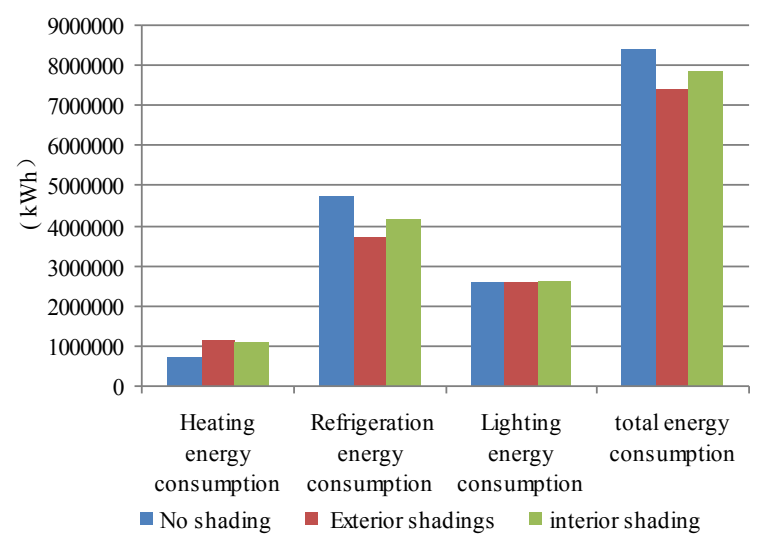

Fig. 11. Effects of sun-shading measure on building energy consumption 


\section{Conclusions}

To solve the high building energy consumption of waiting halls of railway stations and explore the energy-saving potential of such structures, the building energy consumption of the waiting hall of the Chengdu East Railway Station was simulated and the composition characteristics of this building energy consumption were discussed. The influences of envelope structural parameters, area ratio of skylight, and sun-shading measures on the energy consumption of waiting hall of railway stations were analyzed through simulation. The main conclusions of the study are as follows:

(1) The building energy consumption of the waiting hall of the Chengdu East Railway Station was simulated. The results show that air-conditioning system has the highest energy consumption $(64.9 \%)$, followed by the illumination system $(30.9 \%)$.

(2) Simulation analysis of energy consumption in the building model with different envelope structures shows that the thermal properties of glass curtain wall influence the annual building energy consumption significantly. Glass curtain wall with coated insulating glass contributes to the low building energy consumption. Furthermore, the annual building energy consumption presents a V-shaped variation with the increase in area ratio of skylight and reaches the valley at $20 \%$ area ratio of skylight.

(3) Simulation analysis of energy consumption in the building model with internal and external sun-shading measures at the glass curtain wall and skylight reveals that sun-shading measures can reduce building energy consumptions significantly, especially the external sunshading measure.

Simulation analysis on the influences of the thermal properties of building envelope on the energy consumption of waiting hall of railway stations was conducted. The findings provide theoretical basis for energy efficiency design for waiting halls of railway stations in regions with hot summer and cold winter. Moreover, the findings are significant in reducing building energy consumption. However, the influences of running control strategies of airconditioning and illumination systems on building energy consumption were not analyzed given the limited simulation tools and methods. Thus, the topic requires much further research.

\section{Acknowledgements}

The work was supported by Science Technology Research and Development Projects of TangShan (No. 15110204a) and Key laboratory fund project of Tangshan College (No. 13009B).

This is an Open Access article distributed under the terms of the Creative Commons Attribution Licence

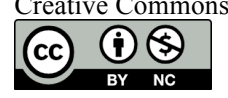

\section{References}

1. Qinbo Li, Lixiong Wang, Rui Dang, Gang Liu, Heng Liu, "Energy-saving design and reconstruction of train station waiting room based on thermal comfort". Building Energy Efficiency, 42(277), 2014, pp. 97-102.

2. Baomin Huang, Jianzhang Zhu, "Discussion on the Installation Mode of Air-conditioned Computer Room in Railway Passenger Station Waiting Room". Railway Standard Design, ,s2, 2010,pp.810 .

3. Mohammad,S.A., "Performance characteristics and practical applications of common building thermal insulation materials". Building and Environment, 40(3) 2005,pp. 353-366.

4. Dezhong Huang, Jibao Shen, "Summarization of Building Energy Saving Technology". Acta Energiae Solaris Sinica, 28 (6), 2008,pp.682-687.

5. Kossecka,E, Kosny. J., "Influence of insulation configuration on heating and cooling loads in a continuously used building". Energy and Buildings, 34(4), 2002, pp.321-331.

6. Tummup. P, Chirarattananon. s, Hien.V. D., "thermal performance of insulated walls enclosing residential spaces in Thailand". Energy and Building, 61(6), 2013, pp.323-332.

7. Chirarattananon.S,Hien.V.D., Tummu.P., "Thermal performance and cost effectiveness of wall insulatin under Thai climate". Energy and Building, 45(2), 2012,pp.82-90.

8. Ihara.T., Gustavsen.A.,Jelle. B. P., "Effect of façade components on energy efficiency in office buildings". Applied Energy, 158(22), 2015, pp.422-432.
9. Pan. D., Chan. M., Deng. S., "The effects of external wall insulation thickness on annual cooling and heating energy uses under diffident climates". Applied Energy, 97(9), 2012, pp.313318.

10. Fang Ruan, Xiaoqian Qian, Yaotai Zhu, Minli Wu, "Effect of Intermittent Energy Use in Room on Internal and External Thermal Insulation of Wall”. Journal of Zhejiang University, 50(1), 2016, pp.1-7.

11. Hongliang Chu, Shibing Sun, Chenglong Wan, "Simulation Analysis of Building Energy Saving Effect of Glazing Film”. New Building Materials, 12(03), 2015, pp.24 27.

12. Cheung,R.J, Fuller,M.B., "Luther.Energy-efficient envelope design for high-rise apartments". Energy and Building, 37(7) 2005, pp.3748

13. Athanassios, Tzempelikos, Andreas. K., Athienitis, "The impact of shading design and concrol on building cooling and lighting demand". solor energy, 81(8), 2007, pp.369-382.

14. Peihao Wang, Dongyang Wang, Xilian Luo, "Energy consumption simulation and energy - saving analysis of existing building envelope". Architecture Science, 2, 2007, pp.22-26.

15. Xiaowen Ma, Junyue Liu, Yutong Li, Lian Chen, "Study on comprehensive sunshading effect of Louvers shading and Low-e glass in Nanjing area". Architecture Science, 11, 2006, pp.761-767. 